\title{
Molecular cloning and nucleotide sequence of the gene encoding a calcium-dependent exoproteinase from Bacillus megaterium ATCC 14581
}

\author{
Sabine Kühn and Peter FortnageL* \\ Universität Hamburg, Institut für Allgemeine Botanik, Abteilung Mikrobiologie, Ohnhorststraße 18, \\ 2000 Hamburg 52, Germany
}

(Received 27 May 1992; revised 22 September 1992; accepted 25 September 1992)

\begin{abstract}
The gene nprM encoding the calcium-dependent extracellular proteinase from Bacillus megaterium ATCC 14581 was cloned in the vector pBR322 and expressed in Escherichia coli HB101. The DNA sequence of the cloned 3.7 $\mathrm{kb}$ fragment revealed only one open reading frame consisting of $1686 \mathrm{bp}$ with a coding capacity of 562 amino acid residues. A predicted Shine-Dalgarno (SD) sequence was observed 9 bp upstream from the presumptive translation start site (ATG). A possible promoter sequence (TAGACG for the -35 region and TATAAT for the -10 region) was found about 69 bp upstream of the ATG start site. The deduced amino acid sequence exhibited a 24 amino acid residue signal peptide and an additional polypeptide 'pro' sequence of 221 amino acids preceding the putative mature protein of 317 amino acid residues. Amino acid sequence comparison revealed 84.5\% homology between the mature protein and that of a thermolabile neutral protease from $B$. cereus. It also shares $73 \%$ homology with the thermostable neutral proteases of B. thermoproteolyticus and B. stearothermophilus. The zinc-binding sites and the catalytic residues are completely conserved in all four proteases. $\mathrm{NprM}$ has a temperature optimum of $58{ }^{\circ} \mathrm{C}$, a $\mathrm{pH}$ optimum of between 6.4 and 7.2 , and is stimulated by calcium ions and inhibited by EDTA. These results indicate that the enzyme is a neutral (metallo-) protease.
\end{abstract}

\section{Introduction}

Bacterial species of the genus Bacillus secrete a variety of enzymes, some of which are of commercial importance, particularly $\alpha$-amylases and proteinases (Debabov, 1982). In the past, many protease genes from representatives of the genus have been cloned and characterized. For example, Bacillus subtilis secretes many different extracellular proteases into the culture medium, especially at the end of the exponential growth phase (Stahl \& Ferrari, 1984; Wong et al., 1984; Yang et al., 1984; Rufo et al., 1990; Sloma et al., 1990; Wu et al., 1990; Tran et al., 1991). The neutral proteases from B. stearothermophilus (Fuji et al., 1983; Takagi et al., 1985; Kubo et al., 1988; Kubo \& Imanaka, 1988; Nishiya \& Imanaka, 1990), B. thermoproteolyticus (thermolysin) (Latt et al., 1969; Staufer, 1971; Titani et al., 1972; Matthews et al., 1972), B. cereus (Sidler et al., 1986; Pauptit et al., 1988), and

* Author for correspondence. Tel. (0049) 4082282444 ; fax (0049) 4082282431

The sequence data reported in this paper have been submitted to Gen Bank and have been assigned the accession number X61380 NPRM.
B. caldolyticus (van den Burg et al., 1991) have been purified and the genes cloned and characterized. All of these proteases are synthesized in the form of 'prepro' enzymes.

Relatively little is known about proteases produced by $B$. megaterium. An intracellular protease initiates the extensive protein degradation that occurs during the early stages of spore germination (Loshon \& Setlow, 1982). Another protease from B. megaterium, known as megateriopeptidase (Millet, 1968), is a hydrophobic aminoendopeptidase. It is the only known extracellular endopeptidase produced and excreted by $B$. megaterium. This protease is synthesized during both growth and sporulation. The formation of the enzyme during growth is repressed by free amino acids and glucose or acetate (Chaloupka, 1969; Millet \& Aubert, 1969). Its synthesis during sporogenesis is rather insensitive to repression (Chaloupka et al., 1982).

Megateriopeptidase is most active at $\mathrm{pH} \mathrm{7.2,} \mathrm{is}$ stabilized by calcium ions, and is inactivated by $o$ phenanthroline. These results classify it as a neutral (metallo-) proteinase. Its specificity for a series of dipeptide substrates is similar to that of thermolysin (Millet \& Archer, 1969). Other similarities with thermo- 
lysin, including a partial crossreaction with antithermolysin serum which causes loss of enzyme activity with the precipitin reaction, have already been described (Keay et al., 1971). In this paper, the cloning of the gene for a $B$. megaterium extracellular metalloproteinase is described, together with its characterization, and some properties of the gene product.

\section{Methods}

Bacterial strains and cloning vectors. The B. megaterium type strain, ATCC 14581 (Skerman et al., 1980), was used as a source of the chromosomal DNA. E. coli HB101 (Boyer \& Roulland-Dussoix, 1969) and E. coli JM101 (Messing, 1983) were used as hosts for cloning and sequencing experiments. The shuttle plasmid $\mathrm{pJK} 302$, consisting of the vectors pBR322 $(4.36 \mathrm{~kb})$ and pBC16-1 $(2.84 \mathrm{~kb})$ fused at the EcoRI restriction sites (Kreft \& Hughes, 1982), and the plasmids pBR322 (Bolivar et al., 1977), pIBI30, and pIBI31 (IBI) were used as vectors.

Media and growth conditions. E. coli strains harbouring plasmids were cultivated in LB broth (Maniatis et al., 1982) containing $50 \mu \mathrm{g}$ ampicillin $\mathrm{ml}^{-1}$ (Serva) at $37^{\circ} \mathrm{C}$. Skim milk $(0.8 \%)$ was added to solid media to visualize protease activity. Solid media contained $1.5 \%(\mathrm{w} / \mathrm{v})$ agar.

Preparation of DNA. B. megaterium ATCC 14581 was grown in LB broth in Erlenmeyer flasks, filled to $1 / 10$ their nominal volume, at $37^{\circ} \mathrm{C}$ in a reciprocal waterbath shaker at 120 strokes per min. Cultures were harvested by centrifugation $\left(9800 \mathrm{~g}, 10 \mathrm{~min}\right.$ at $\left.4{ }^{\circ} \mathrm{C}\right)$ during exponential growth $\left(\mathrm{OD}_{578}=1 \cdot 0\right)$. Genomic DNA was prepared as described by Saito \& Miura (1963). Plasmid DNA was isolated by the alkaline extraction procedure of Birnboim \& Doly (1979).

Cloning of the nprM gene. Genomic DNA from B. megaterium ATCC 14581 was partially digested with Sau3A. Size fractionated fragments (10-20 kb) were ligated into BamHI-digested pJK302. The ligation mixture was used to transform competent cells of $E$. coli HB101 (Kushner, 1978). Ampicillin-resistant transformants were transferred to skim milk media plates to detect the production of exoprotease, as indicated by the presence of clear lysis zones after $18 \mathrm{~h}$ incubation at $37^{\circ} \mathrm{C}$.

Hybridization analysis of DNA digests. EcoRI digests of $B$. megaterium ATCC 14581 genomic DNA $(5 \mu \mathrm{g})$ were subjected to electrophoresis in a $0.8 \%$ agarose gel. After denaturation by soaking the gel with $0.5 \mathrm{M}-\mathrm{NaOH} / 1 \mathrm{M}-\mathrm{NaCl}$ for $30 \mathrm{~min}$ at room temperature the DNA was transferred onto a nylon membrane (Pall) (Southern, 1975). Approximately $0.5 \mu \mathrm{g}$ of the $A c c \mathrm{I}$ fragment, from the $E c o \mathrm{RI} / E c o \mathrm{RV}$ insert encoding for $n p r M$, was labelled with biotin-7-dATP and used as a probe for hybridization analysis of the $E c o$ RI digests of the genomic DNA on the membrane, by use of a DNA labelling and detection kit (BRL).

Nucleotide sequencing. Restriction fragments were subcloned into pIBI30 or pIBI31. The plasmid DNA was isolated by the alkaline extraction procedure of Birnboim \& Doly (1979), denaturated by treatment with $2 \mathrm{~m}-\mathrm{NaOH} / 1 \mathrm{~mm}-\mathrm{Na}_{2} \mathrm{EDTA}$, and the nucleotide sequence determined by the chain-termination method of Sanger et al. (1977), using labelled $\left[\alpha-{ }^{35}\right.$ S $]$ ATP and the T7 sequencing kit (Pharmacia). Approximately 330 bases were read from each sample. Both strands of the gene were sequenced.

Assay of neutral protease activity. E. coli transformants carrying the recombinant plasmid DNA were cultivated in LB broth supplemented with ampicillin at $37^{\circ} \mathrm{C}$ for $6 \mathrm{~h}$. Cells from $200 \mathrm{ml}$ of the culture were harvested by centrifugation $\left(9800 \mathrm{~g}, 10 \mathrm{~min}\right.$ at $\left.4{ }^{\circ} \mathrm{C}\right)$ and were suspended in $10 \mathrm{ml} 10 \mathrm{~mm}$-Tris/ $\mathrm{HCl}, \mathrm{pH} 7 \cdot 4$. The cell suspension was disrupted in a French press at 20000 p.s.i. at $4{ }^{\circ} \mathrm{C}$ and the cell debris removed by centrifugation $\left(12000 \mathrm{~g}, 20 \mathrm{~min}\right.$ at $\left.4{ }^{\circ} \mathrm{C}\right)$. The protease activity of the supernatant was assayed with azocasein $\left(10 \mathrm{mg} \mathrm{ml}^{-1}\right)$ (Sigma). Samples $(0.5 \mathrm{ml})$ of the diluted enzyme extract and $5 \mathrm{mg}$ azocasein were incubated for $20 \mathrm{~min}$ at $37^{\circ} \mathrm{C}, 1.5 \mathrm{ml}$ TCA $(5 \%, \mathrm{w} / \mathrm{v})$ was added and the mixture was incubated for $30 \mathrm{~min}$ at $37^{\circ} \mathrm{C}$. The denatured proteins were removed by centrifugation $(16000 \mathrm{~g}, 2 \mathrm{~min})$. The absorbance of the supernatant was measured at $400 \mathrm{~nm}$. Cultures of $E$. coli containing pBR322 served as control.

\section{Results}

Cloning of nprM in E. coli HB101

Among several thousand ampicillin-resistant E. coli HB101 transformants, one was found to liberate protease activity into the medium, as detected by a clear zone around the colony on skim milk nutrient plates. This protease-producing transformant contained a $24 \mathrm{~kb}$ recombinant plasmid, consisting of the vector pJK302 and a $17 \mathrm{~kb}$ insert. By shotgun cloning this $17 \mathrm{~kb}$ insert was reduced to $3.7 \mathrm{~kb}$ (pSK44), during which treatment the component of $\mathrm{pBC} 16-1$ from the plasmid $\mathrm{pJK} 302$ was lost. Therefore pSK44 consisted of the vector pBR322 and an EcoRI/EcoRV insert coding for $n p r M$ (Fig.1).

\section{Characterization of $\mathrm{NprM}$}

To confirm the cloning of a neutral protease gene, properties of the cloned protease were determined in crude cell extracts. The protease activity was inhibited

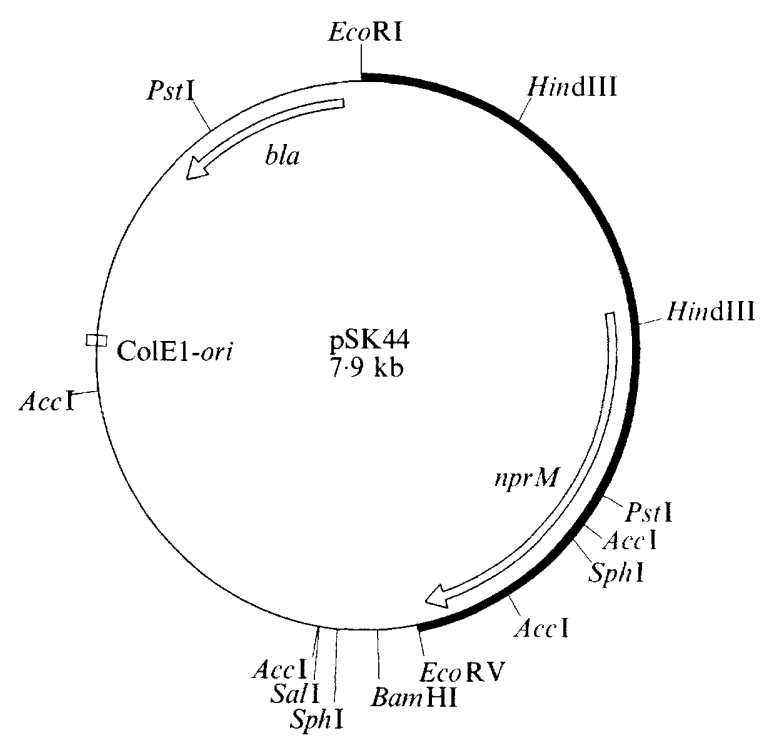

Fig. 1. Restriction map of the plasmid pSK44 consisting of the vector pBR322 (thin line) and the cloned EcoRI/EcoRV fragment from genomic DNA of B. megaterium ATCC 14581 (thick line). The arrows indicate the regions which are essential for expression of ampicillin resistance and protease activity. 


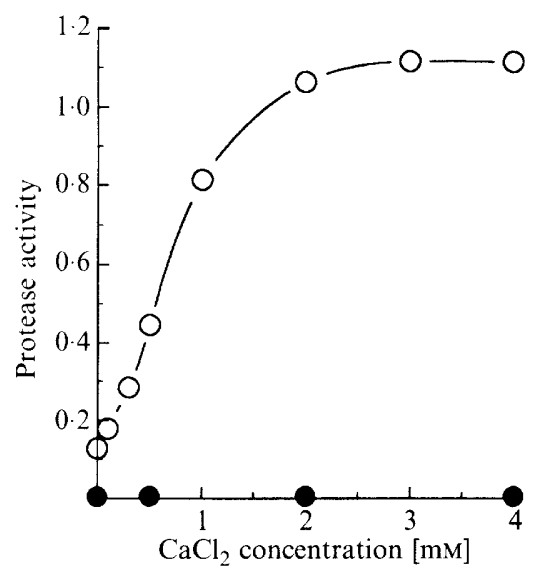

Fig. 2. Calcium activation of NprM in crude cell extracts of $E$. coli $/ \mathrm{pSK} 44$. Protease activity is in arbitrary units $\left(\mathrm{OD}_{400} / 20 \mathrm{~min}\right) . \bigcirc$, Crude cell extract from E. coli/pSK $44 ;-$, crude cell extract from E. coli/pBR322 (control).

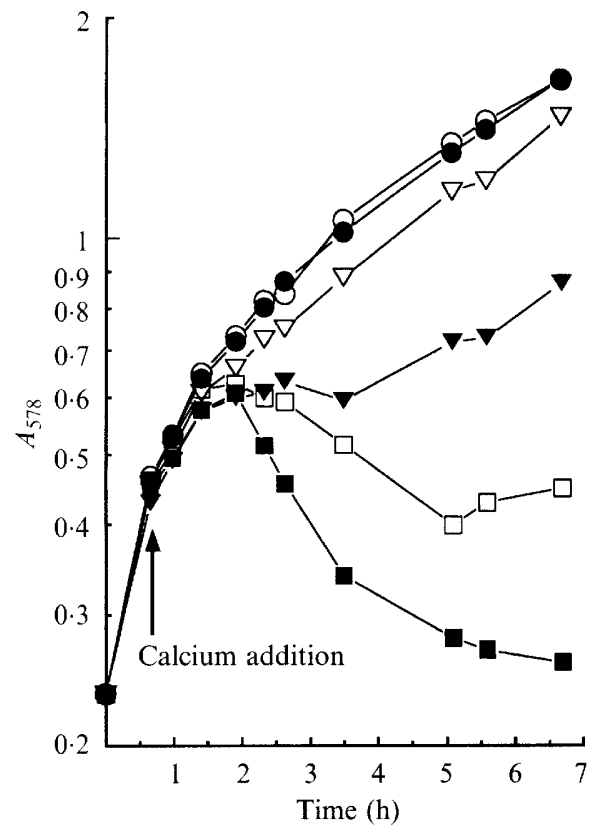

Fig. 3. Calcium-induced cell lysis during growth of $E$. coli/pSK44. Calcium choride concentration (mM): $0,0.05 ; 0,0.1 ; \nabla, 0.5 ; \nabla, 1.0$; $\square, 2 \cdot 0$; and $\square, 3 \cdot 0$. by EDTA, had a pH optimum between 6.4 and 7.2, and a temperature optimum of $58{ }^{\circ} \mathrm{C}$. The protease activity was strongly dependent on the presence of calcium ions (Fig. 2). Control experiments using extracts of E. coli/pBR322 showed negligible protease activity with azocasein as substrate. This background activity was significantly below the basic actitivy of $E$. coli/pSK 44 without activation by calcium addition. This basal level activation in extracts of E. coli/pSK 44 may be caused by traces of calcium always present in the culture.

These results indicated that the main protease activity in the extracts of E. coli/pSK44 was a neutral (metallo-) protease.

Growth of E. coli/pSK44 without addition of extra calcium to the medium appeared normal. No protease was detectable in the culture fluid after removal of the bacterial cells and addition of $2 \mathrm{~mm}$ calcium. However. if calcium was added to a growing culture in concentrations higher than $0.5 \mathrm{~mm}$, lysis of the bacterial cells occurred (Fig. 3). Microscopic inspection of the cells at this stage revealed spheroplast-like structures.

In order to confirm that the $3.7 \mathrm{~kb}$ insert of pSK 44 came from $B$. megaterium, Southern hybridization analysis of chromosomal DNA was performed using the dATP-7-biotin-labelled $0.47 \mathrm{~kb}$ AccI fragment of pSK 44 as a probe. The labelled probe hybridized with a single $4 \mathrm{~kb}$ fragment in EcoRI digests (data not shown).

\section{Nucleotide sequence of nprM}

The nucleotide sequence of the $n p r M$ gene and its flanking regions was determined. The sequencing strategy is depicted in Fig. 4. The sequence revealed a single large ORF consisting of 1686 nucleotides, with a coding capacity for 562 amino acid residues (Fig. 5). A putative Shine-Dalgarno (SD) sequence (AGGGATAGGGA) was found $9 \mathrm{bp}$ upstream from a likely translation start site (ATG) (Moran et al., 1982). The calculated free energy of binding $(\Delta G)$ of this ribosome-binding site (Tinoco et al., 1973) with the $3^{\prime}$ end of the 16S rRNA from B. subtilis is $-74.4 \mathrm{~kJ} \mathrm{~mol}^{-1}$. This $\Delta G$ value as well as the distance between the initiation codon and the

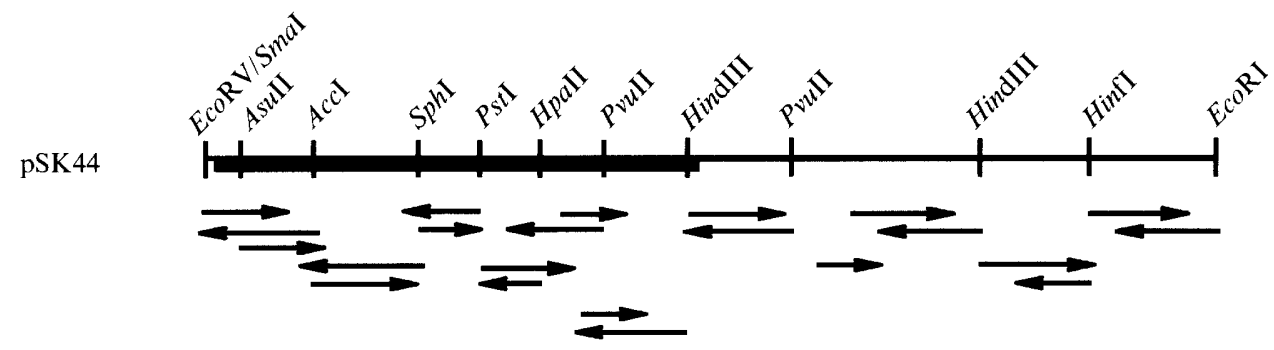

Fig. 4. DNA-sequencing strategy. Subclones of the $E c o$ RI/EcoRV fragment in pIBI30 or pIBI31 were used for sequencing. Thick line: ORF of the $n p r M$ gene. The arrows represent the directions and the extents of the sequences. 
TAATTTAAATAGGTAAAAAGACTTATTGCAAAGATTTATTCTTAATTCATAATAATAG GAATATTAAAAATAATATAATGACGTAGTAATTTTTAGTTGCTATAATGTTGCTAATTAT $-35$ $-10$ 1 CTCAATTAACAGAAAAATGCGgTAATTAAATTACTAGgGATAGGGAGAAAAAACTATG

AAAAAGAAAAAACAGGCTTTAAAGGTATTATTATCAGTTGGTATCCTTTCTTCATCATTT

$\begin{array}{lllllllllllllllllllll}21 & K & K & K & K & Q & A & L & K & V & L & L & S & V & G & I & L & S & S & S & F\end{array}$ GCTTTTGCACATACGAGCAGTGCGGCGCCAAATAATGTACTTTCAACCGAAAAGTATAAC

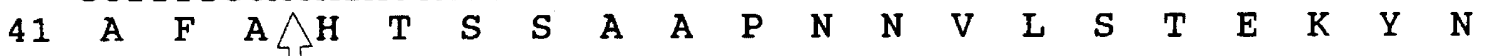
AAAGAAATTAAATCTCCTGAGTTTATTTCTGGAAAGCTTTCAGGCCCATCATCACAGAAA

$\begin{array}{lllllllllllllllllllll}61 & K & E & I & K & S & P & E & F & I & S & G & K & L & S & G & P & S & S & Q & K\end{array}$ GCTCAAGACGTCGTATTTCATTATATGAATACAAATAAAGACAAATATAAATTAGGAAAC

$\begin{array}{llllllllllllllllllllll}81 & A & Q & D & V & \text { V } & \text { F } & \text { H } & \text { Y } & \text { M } & \text { N } & \text { T } & \text { N } & \text { K } & \text { D } & \text { K } & \text { Y } & \text { K } & \text { L } & G & \text { N }\end{array}$ GAAAGTGCTCAAAATTCATTTAAAGTGACAGAAGTAGTGAAAGATCCCGTTGAACAAGCA 303 $\begin{array}{lllllllllllllllllllll}101 & E & S & A & Q & N & S & F & K & V & T & E & V & V & K & D & P & V & E & Q & A\end{array}$ ACCGTTGTACGCTTGCAGCAGGTATATAATAATATTCCTGTTTGGGGATCTACTCAATTA 363 $\begin{array}{lllllllllllllllllllll}121 & T & V & V & R & L & Q & Q & V & Y & N & N & I & P & V & W & G & S & T & Q & L\end{array}$ GCACACGTAGCGAAAGATGGAACCTTAAAAGTTGTATCAGGTACAGTAGCTCCTGATTTA

$\begin{array}{lllllllllllllllllllll}141 & A & \text { H } & \text { V } & \text { A } & \text { K } & \text { D } & \text { G } & \text { T } & \text { L } & \text { K } & \text { V } & \text { V } & \text { S } & G & \text { T } & \text { V } & \text { A } & \text { P } & \text { D } & \text { L }\end{array}$ GATAAAAAGGAAAAGCTAAAAGGACAGAAGCAAGTTGACAGCAAAAAGGCGATTCAAGCA 483 $\begin{array}{lllllllllllllllllllll}161 & D & K & K & E & K & \text { L } & K & G & Q & K & Q & V & D & S & K & K & A & I & Q & A\end{array}$ GCTGAAAAAGACTTAGGCTTTAAACCGACTTATGAAAAATCCCCTTCATCTGAACTGTAT 543

$\begin{array}{lllllllllllllllllllll}181 & A & E & K & D & L & G & F & K & P & T & Y & E & K & S & P & S & S & E & L & Y\end{array}$ GTTTATCAAAATGCTTCAGACACAACGTATGOTTATGTAGTAAATTTAAATTTCTTAAGC 603 $\begin{array}{lllllllllllllllllllll}201 & V & Y & Q & N & A & S & D & T & T & Y & A & Y & V & V & N & \text { L } & N & F & L & S\end{array}$ CCTGAACCAGGTAATTATTATTACTTTGTTGATGCTATTAGCGGTAAAGTGCTAGATAAG

$\begin{array}{lllllllllllllllllllll}221 & P & E & P & G & N & Y & Y & Y & F & V & D & A & I & S & G & K & V & \text { L } & \text { D } & \text { K }\end{array}$ TACAATACGATTGATTCCGTAGCTGGTCCAAAAGCCGATGTGAAGCAAGCGGCAAAGCCG 723 $\begin{array}{lllllllllllllllllllll}241 & Y & N & T & I & D & S & V & A & G & P & K & A & D & V & K & Q & A & A & K & P\end{array}$ GCAGCGAAACCTGTAACAGGAACAAATACTATTGGCTCAGGTAAAGGAGTGCTTGGAGAT 783 $\begin{array}{lllllllllllllllllllll}261 & A & A & K & P & V & T & G & T & N & T & I & G & S & G & K & G & V & \text { L } & G & \text { D }\end{array}$ Mature

ACTAAATCTTTAAAGACAACGTTATCTAGTTCCACTTACTACTTACAAGATAATACAAGA 843 $\begin{array}{lllllllllllllllllllll}281 & \mathrm{~T} & \mathrm{~K} & \mathrm{~S} & \mathrm{~L} & \mathrm{~K} & \mathrm{~T} & \mathrm{~T} & \mathrm{~L} & \mathrm{~S} & \mathrm{~S} & \mathrm{~S} & \mathrm{~T} & \mathrm{Y} & \mathrm{Y} & \mathrm{L} & \mathrm{Q} & \mathrm{D} & \mathrm{N} & \mathrm{T} & \mathrm{R}\end{array}$ GGAGCGACAATCTATACGTATGATGCAAAAAATCGTACATCTCTGCCAGGTACACTATGG 903 $\begin{array}{lllllllllllllllllllll}301 & G & A & T & I & Y & T & Y & D & A & K & N & R & T & S & L & P & G & T & L & W\end{array}$ GCAGACACGGATAATACGTACAATGCAACCCGCGATGCAGCTGCAGTAGATGCTCACTAT 963 $\begin{array}{lllllllllllllllllllll}321 & A & D & T & D & N & T & Y & N & A & T & R & D & A & A & A & V & D & A & H & Y\end{array}$ 
TATGCAGGCGTGACATATGATTATTACAAAAACAAATTTAACCGCAACTCCTATGACAAT 1023

$\begin{array}{lllllllllllllllllllll}341 & Y & A & G & V & T & Y & D & Y & Y & K & N & K & F & N & R & N & S & Y & D & N\end{array}$

GCAGGACGTCCGCTAAAATCGACTGTTCATTATAGCAGCGGTTACAATAATGCGTTTTGG 1083

$\begin{array}{lllllllllllllllllllll}361 & A & G & R & P & \text { L } & K & \text { K } & \text { T } & \text { V } & \text { H } & \text { Y } & \text { S } & \text { S } & G & \text { Y } & \text { N } & \text { N } & \text { A } & F & \text { W }\end{array}$

AATGGCTCTCAAATGGTATACGGAGATGGAGATGGAACTACTTTTGTTCCGCTATCAGGA 1143

$\begin{array}{lllllllllllllllllllll}381 & N & G & S & Q & M & V & Y & G & D & G & D & G & T & T & F & V & P & \text { L } & S & G\end{array}$

GGATTAGATGTTATCGGACATGAATTGACGCATGCGCTCACAGAAAGAAGTTCTAATTTA 1203

$\begin{array}{lllllllllllllllllllll}401 & G & L & D & V & I & G & H & E & L & T & H & A & L & T & E & R & S & S & N & L\end{array}$

ATCTATCAATATGAATCAGGTGCATTAAACGAGGCAATTTCCGATATTTTCGGAACATTG 1263

$\begin{array}{lllllllllllllllllllll}421 & I & Y & Q & Y & E & S & G & A & L & N & E & A & I & S & D & I & F & G & T & L\end{array}$

GTAGAATACTATGACAACCGTAATCCAGATTGGGAAATTGGAGAAGATATTTATACGCCT 1323

$\begin{array}{lllllllllllllllllllll}441 & \mathrm{~V} & \mathrm{E} & \mathrm{Y} & \mathrm{Y} & \mathrm{D} & \mathrm{N} & \mathrm{R} & \mathrm{N} & \mathrm{P} & \mathrm{D} & \mathrm{W} & \mathrm{E} & \mathrm{I} & \mathrm{G} & \mathrm{E} & \mathrm{D} & \mathrm{I} & \mathrm{Y} & \mathrm{T} & \mathrm{P}\end{array}$

GGTACAAGCGGTGATGCGCTTCGTTCAATGAGCAACCCAGCGAAATATGGAGATCCAGAT 1383

$\begin{array}{lllllllllllllllllllll}461 & G & T & S & G & D & A & \text { L } & \text { R } & \text { S } & \text { M } & \text { S } & \text { N } & \text { P } & \text { A } & \text { K } & Y & G & \text { D } & \text { P } & \text { D }\end{array}$

CATTATTCAAAGCGCTATACAGGTTCTAGTGACAACGGCGGAGTTCATACAAACAGCGGT 1443

$\begin{array}{lllllllllllllllllllll}481 & H & Y & S & K & R & Y & T & G & S & S & D & N & G & G & V & H & T & N & S & G\end{array}$

ATTATCAACAAAGCTGCCTACTTGCTAGCTAACGGAGGAACGCATTACGGGGTTACTGTA 1503

$\begin{array}{lllllllllllllllllllll}501 & I & I & N & K & A & A & Y & L & L & A & N & G & G & T & H & Y & G & V & T & V\end{array}$

ACAGGCATCGGCGGCGATAAGCTAGGGAAAATTTATTACCGTGCTAATACGCTATACTTC 1563

$\begin{array}{lllllllllllllllllllll}521 & T & G & I & G & G & D & K & L & G & K & I & Y & Y & R & A & N & T & \text { L } & Y & F\end{array}$

ACTCAGTCTACAACGTTTAGCCAAGCGCGTGCAGGTTTAGTACAAGCTGCTGCTGATCTA 1623

$\begin{array}{lllllllllllllllllllll}541 & T & Q & S & T & T & F & S & Q & A & R & A & G & L & V & Q & A & A & A & D & L\end{array}$

TACGGTTCAGGCTCTCAAGAAGTAATCTCAGTAGGTAAGTCATTTGACGCAGTTGGTGTT 1683

$\begin{array}{llllllllllllllllllllll}561 & Y & G & S & G & S & Q & E & V & I & S & V & G & K & S & F & D & A & V & G & V\end{array}$

CAATAAGTTATAAACCAAAAGTCGCAAGATAAATGAGGTATCTTACGACTCTCTATACTA 1743

562 Q

CCTTACTACCAATAAAgGAGTACTCGTATAAATATATTACAGTACTCCTTTATTTTATGT 1803

Fig. 5. Nucleotide sequence and derived amino acid sequence of the neutral protease gene nprM of Bacillus megaterium. The nucleotide sequence is numbered from the first base of the translation start site. The predicted amino acid sequence is shown beneath the nucleotide sequence. Putative Shine-Dalgarno (SD) and promoter $(-35$ and -10$)$ sequences are shown by solid lines below the nucleotide sequence. Horizontal arrows indicate terminator-like inverted-repeat sequences. The putative signal peptide cleavage site (open arrow) and the maturation site (filled arrow) of the predicted pre-pro-enzyme are indicated.

putative ribosomal binding site are in good agreement with other reported ribosome-binding sites from several genes of different Bacillus strains (Hager \& Rabinowitz, 1985).

A presumptive promoter sequence $(-35$ region: TAGACG ; - 10 region: TATAAT), was observed $69 \mathrm{bp}$ upstream of the ATG start codon. The promoter shows good agreement with the consensus sequence for $\sigma^{70}$ - promoters of E. coli (Hawley \& McClure, 1983) and the $\sigma^{A}$-promoters of B. subtilis (Moran et al., 1982).

Two inverted-repeat sequences were found downstream of the termination codon (TAA) of the ORF (from nucleotides 1700-1730 and from nucleotides 1752-1795). The $\Delta G$ values of these stem-loop structures were calculated to be $-54.4 \mathrm{~kJ} \mathrm{~mol}^{-1}$ and $-80.1 \mathrm{~kJ}$ $\mathrm{mol}^{-1}$, respectively. These sequences might function as 
(a) VTGTNTIGSGKGVLGDTKSLKTTLSS-STYY----LQDNTRGATIYTYDAKNR-TSLPGT

(b) $\mathbf{I} \cdots \mathbf{S} \cdots \mathbf{V} \cdot \mathbf{R} \cdots \cdot \mathbf{Q} \cdot \mathbf{N I N} \cdot \mathbf{Y}--\cdots \cdot-\mathbf{Y} \cdot \cdots \cdot \mathbf{D G} \cdot \mathbf{F} \cdots \cdots \mathbf{Y} \cdot-\mathbf{T} \cdot \cdots \mathbf{S}$

(c) $\cdot \mathbf{A} \cdot \mathbf{S} \cdot \mathbf{V} \cdot \mathbf{V} \cdot \mathbf{R} \cdot \cdots \cdot \mathbf{Q} \cdot \mathbf{Y I N} \cdot \mathbf{Y} \cdot \mathbf{Y Y G} \cdot--\mathbf{Y} \cdot \cdots \cdot \mathbf{B G} \cdot \mathbf{F} \cdot \cdots \mathbf{G R} \cdot \mathbf{-} \cdot \mathbf{V} \cdot \cdots \mathbf{S}$

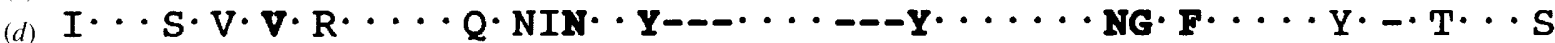

(e) $\cdot \mathbf{A} \cdot \mathbf{A S} \cdot \mathbf{V} \cdot \mathbf{V} \cdot \mathbf{R} \cdot \cdots \cdot \mathbf{Q} \cdot \mathbf{Y I N} \cdot \mathbf{Y}-\cdots \mathbf{S} \cdot \mathbf{G Y Y Y} \cdots \cdots \cdot \mathbf{B G} \cdot \mathbf{F} \cdot \cdots \mathbf{R} \cdot-\cdot \mathbf{V} \cdot \cdots \mathbf{S}$

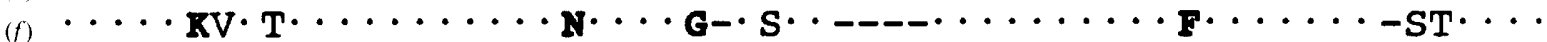

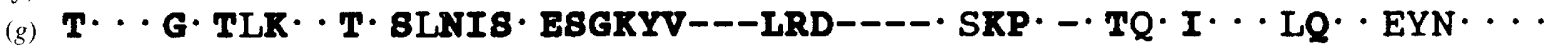

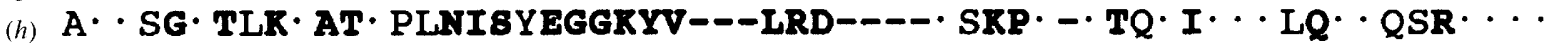

(a) LWADTDNTYNATRDAAAVDAHYYAGVTYDYYKNKFNRNSYDNAGRPLKSTVHYSSGYNNA 120

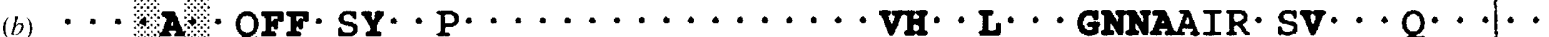

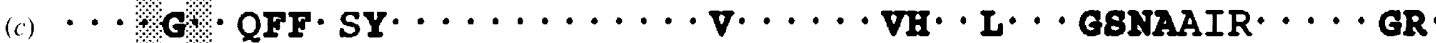

$\cdots \mathbf{A} \cdot \mathbf{Q F F} \cdot \mathbf{S Y}$

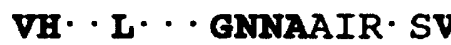

-T. G. QFT. SY

VHG $\cdot$ L - . GSIAAI.

(f) $\cdots \mathbf{A}$. VF $\cdot \mathbf{A Y}$

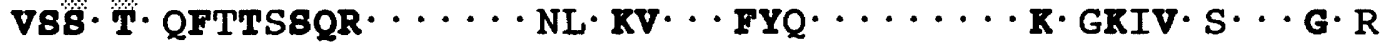

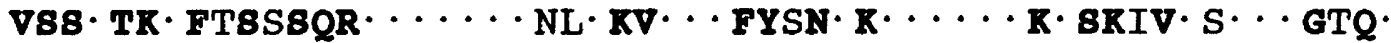

(a) FMNGSQMVYGDGDGTTFVPLSGGLOVIGHETFPLTERSSNLIYQYESGALNEAISDIFG 180

(b)
(c)
(d)
(f)
(g)

(b)

(c)

$(d)$

$(e)$

(f)

(g)

(h)

(a)

(b)

(c)

(d)

(e)

(f)

(g)

(h)

(a)

(b)

(c)

(d)

(e)

(f)

(g)

(h) (a) TLVAYYDNRNPEWEIGEDIYWPGTSGDALFSMSNPAKYGDPDHYS-KRYTGSSDNG---G

240

$$
\begin{aligned}
& \text {... } \mathbf{F} \cdot \mathbf{A} \\
& \cdots \mathbf{F} \cdot \mathbf{A} \cdot \mathrm{K} \\
& \cdots \mathbf{F} \cdot \mathbf{A} \cdot \\
& \cdots \mathbf{F} \text {. } \\
& \text { \% } 8 \text {. } \\
& \mathbf{V A} \cdot \\
& \mathbf{8} \cdot \\
& \mathbf{V} \mathbf{A} \\
& \text { - D . . . . . . . . . TQ } \\
& \text {. } \\
& \text {. D . . . . . . . . T T } \\
& \text { - D. T. }
\end{aligned}
$$

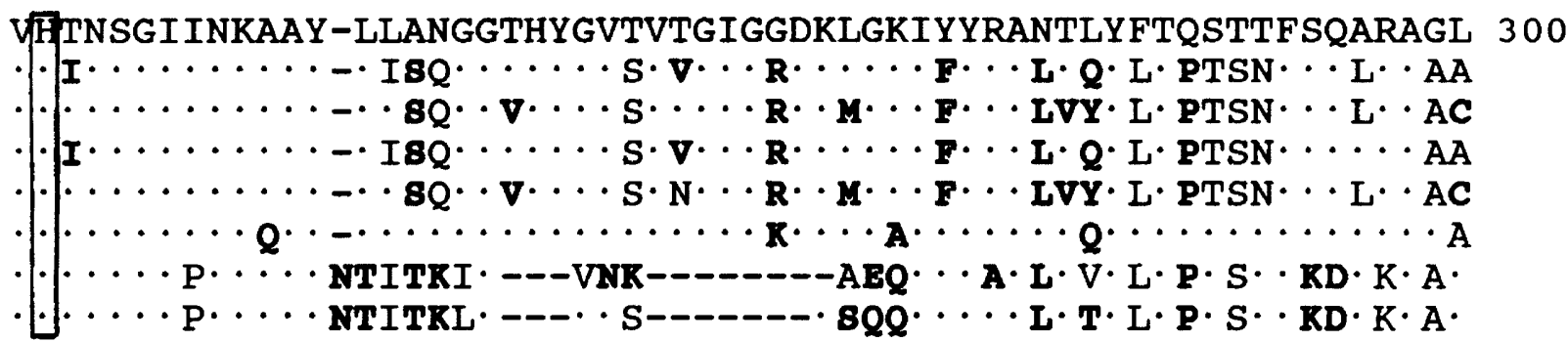

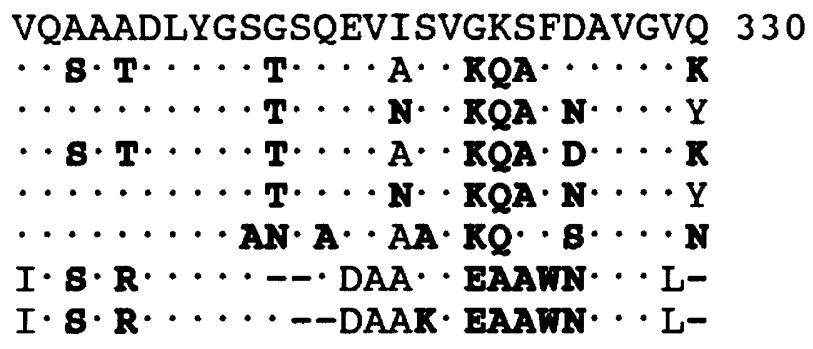


rho-dependent transcription termination signals since they show neither the GC-rich dyad symmetry nor the following run of $\mathrm{A}$ residues that typify rho-independent terminators.

\section{Amino acid sequence of the extracellular neutral protease}

The ORF in the nucleotide sequence codes for a protein of 562 amino acid residues (Fig. 5). This predicted gene product (NprM) exhibits a typical 'pre-pro' structure common to many known extracellular Bacillus proteases. The putative 'pre' structure shows characteristics of a signal peptide (Perlman \& Halverson, 1983; Kreil, 1981), with a positively charged $\mathrm{NH}_{2}$-terminus. Amino acids $1-5$ contain 4 positively charged amino acids (Lys) (n region) and are followed by an $\mathrm{h}$ region, containing a stretch of hydrophobic amino acids (amino acids 6-18) and a potential processing site consisting of 6 amino acids with the Ala-X-Ala recognition cleavage site for a signal peptidase.

The signal peptide (amino acids $1-24$ ) is followed by a putative pro-sequence (amino acids 25-245).

The amino acid sequence of the predicted mature protein was compared with the published sequences of other neutral proteases of bacilli (Fig. 6). By homology comparisons we postulated the mature protein from amino acids 246-562.

Comparison of the amino acid sequence of NprM with other neutral proteases

The sequence of the predicted extracellular form of this protease shows the highest homology to the neutral protease of B. cereus (Sidler et al., 1986) with $84.5 \%$ homology. To the well analysed thermostable neutral protease thermolysin of $B$. thermoproteolyticus (Colman et al., 1972), NprM shows $72.9 \%$ homology; the amino acids with substrate-binding functions in the catalytic centre of thermolysin are, however, fully conserved. Furthermore, there are homologies of over $72 \%$ to the thermostable neutral proteases NPRM (Kubo \& Imanaka, 1988) and NPRT (Takagi et al., 1985) from $B$. stearothermophilus and B. caldolyticus (van den Burg et al., 1991). Only limited homology (less than $50 \%$ ) exists between NprM from B. megaterium and the neutral proteases from $B$. subtilis var. amylosacchariticus (Yoshimoto et al., 1990; Yang, 1984) and B. amyloliquefaciens (Levy et al., 1975; Vasantha et al., 1984).

\section{Discussion}

During the characterization of NprM from $B$. megaterium a strong dependence of the protease activity on calcium ions was found. If the calcium concentration in the culture was kept below $0.5 \mathrm{~mm}$ the bacteria grew normally. At higher concentrations, lysis of the bacterial cells occurred. The protease activity identified around colonies after growth on skim-milk nutrient agar was presumably the result of the release of significant amounts of protease from lysed $E$. coli cells in a highcalcium medium.

The enzyme activity in $E$. coli/pSK 44 cell extracts without addition of calcium was marginal. It apparently arose from traces of calcium present in the culture media which were essential for $E$. coli to grow. The activity increased with elevated concentrations of calcium ions, up to a point of saturation. This activation followed first order kinetics, implying that there are distinctive interactions of the enzyme molecule with calcium ions. This may be due to either an essential requirement for calcium as cofactor for the protease NprM, or a requirement for calcium to facilitate the proper folding to form the active state of the enzyme. Although there are high sequence homologies to thermolysin, this direct calcium dependence of NprM was not described for thermolysin, where calcium has no effect on the activity but rather causes a reduction of its heat resistance (Feder et al., 1971).

Experiments with the NprM-expressing E. coli strain demonstrated the the neutral (metallo-) protease can neither be actively excreted nor passively pass through the membranes of intact cells. In Gram-negative and Gram-positive bacteria, different mechanisms exist for the release of exoenzymes into the periplasmic space or the culture fluid. In addition to the (pre-)pro-structure at the amino terminus in Gram-negative bacteria, many secreted proteins have a special secretion signal at the carboxy-terminal end (Nicaud et al., 1986; Pugsley, 1988), essential for translocating exoenzymes through the outer membrane. The protease of $B$. megaterium might be translocated through the inner membrane of $E$. coli if the Gram-positive pre-pro-structure is recognized and acts as a translocation signal. If so, it might not

Fig. 6. Homology comparison of different neutral proteases of various Bacillus species. (a) the predicted NprM protease of Bacillus megaterium; (b) thermolysin B. thermoproteolyticus; (c) NPR B. caldolyticus; (d) NPR-M B. stearothermophilus; (e) NPR-T B. stearothermophilus; $(f)$ NPR B. cereus; $(g)$ NPR B. amyloliquefaciens; $(h)$ NPR B. subtilis. Homologous amino acids are depicted by a point. Normal print: amino acids that are not identical but belong to the same family; bold print: amino acids that are not identical and belong to different families. Boxes, catalytic amino acids; shading, calcium binding sites. 
penetrate the outer membrane, as it has no C-terminal secretion signal typical of Gram-negatives. At present it is not clear if the Bacillus protease expressed in E. coli remains periplasmic or cytoplasmic. One piece of evidence for the periplasmic location is that the calciumactivated enzyme disrupts the cell wall, causing formation of spheroplast-like structures. This could occur either by a direct interaction of the protease with the peptidoglycan or indirectly by inactivation of enzymes essential for cell wall synthesis.

Amino acid residues necessary for catalytic activity appear to be highly conserved in this class of Bacillus proteases. Zinc plays an essential role for the proteolytic activity of many neutral (metallo-) proteases and functions as the central atom of the neutral (metallo-) proteinase of $B$. megaterium (Keay et al., 1971) and of thermolysin of $B$. thermoproteolyticus. The zinc-binding amino acid residues of thermolysin are His-142, His-146 and Glu-166 (Colman et al., 1972). The same amino acids are found in identical positions in the amino acid sequence of $\mathrm{NprM}$, as is true for the amino acid residues necessary for the formation of hydrogen bonds between the enzyme and the peptide substrate (Try-115, Ala-113, Asn-112, Arg-203) and the amino acid residues which are directly involved in catalysis (His-231, Glu-143) (Kester \& Matthews, $1977 a, b)$.

\section{References}

Birnboim, H.C. \& Doly, J. (1979). A rapid alkaline extraction procedure for screening recombinant plasmid DNA. Nucleic Acids Research 7, 1513-1523.

Bolivar, F., Rodriguez, R. L., Greene, P. J., Betlach, M. C., Heynecker, H. L., Boyer, H. W., Crosa, J. H. \& Falkow, S. (1977). Construction and characterization of new cloning vehicles. Gene 2, 95-113.

Boyer, H. W. \& Roulland-Dussoix, D. (1969). A complementation analysis of the restriction and modification of DNA in E. coli. Journal of Molecular Biology 41, 459-472.

van den Burg, B., Enequist, H. G., van den HaAR, M. E., Eissink, V. G. H., Stulp, B. K. \& Venema, G. (1991). A highly thermostable neutral protease from $B$. caldolyticus: cloning and expression of the gene in B. subtilis and characterization of the gene product. Journal of Bacteriology 173, 4107-4115.

Chaloupka, J. (1969). Dual control of megateriopeptidase synthesis. Annales de l'Institut Pasteur 177, 631-636.

Chaloupka, J., Severin, A. I., Sastry, K. J., Kučerová, H. \& STRNAdOvá, M. (1982). Differences in the regulation of exocellular proteinase synthesis during growth and sporogenesis of B. megaterium. Canadian Journal of Microbiology 28, 1214-1218.

Colman, P. M., Jansonius, J. N. \& Matthews, B. W. (1972). The structure of thermolysin: an electron density map at $2 \cdot 3 \AA$ resolution. Journal of Molecular Biology 70, 701-724.

Debabov, V. G. (1982). The industrial use of bacilli. In The Molecular Biology of the Bacilli, vol. I, pp. 331-364. Edited by D. A. Dubnau. New York: Academic Press.

Feder, J., GarreTt, L. R. \& WiLdi, B. S. (1971). Studies on the role of calcium in thermolysin. Biochemistry 10, 4552-4555

Fujı, M., Takagi, M., Imanaka, T. \& Aiba, S. (1983). Molecular cloning of a thermostable neutral protease gene from $B$. stearothermophilus in a vector plasmid and its expression in $B$. stearothermophilus and B. subtilis. Journal of Bacteriology 154, 831-837.
HaGeR, P. W. \& Rabinowitz, J. C., (1985). Translational specificity in B. subtilis. In The Molecular Biology of the Bacilli, vol. II, pp. 1-32. Edited by D. A. Dubnau. New York: Academic Press.

Hawley, D. K. \& MCClure, W. R. (1983). Compilation and analysis of E. coli promoter DNA sequences. Nucleic Acids Research 11, $2237-2255$.

Keay, L., Feder, J., Garrett, L. R., Moseley, M. H. \& Cirulis, N. (1971). B. megaterium neutral protease, a zinc-containing metalloenzyme. Biochimica et Biophysica Acta 229, 829-835.

Kester, W. R. \& MATthews, B. W. (1977a). Crystallographic study of the binding of dipeptide inhibitors to thermolysin: implications for the mechanism of catalysis. Biochemistry 16, 2506-2516.

Kester, W. R. \& Matthews, B. W. (1977b). Comparison of the structure of carboxypeptidase A and thermolysin. Journal of Biological Chemistry 252, 7704-7710.

KREFT, J. \& Hughes, C. (1982). Cloning vectors derived from plasmids and phage of Bacillus. Current Topics in Microbiology and Immunology 96, 1-17.

KreIL, G. (1981). Transfer of proteins across membranes. Amual Review of Biochemistry 50, 317-348.

Kubo, M., Murayama, K., Seto, K. \& Imanaka, T. (1988). Highly thermostable neutral protease from B. stearothermophilus. Journal of Fermentation Technology 66, 13-17.

Kubo, M. \& Imanaka, T. (1988). Cloning and nucleotide sequence of the highly thermostable neutral protease gene from $B$. stearothermophilus. Journal of General Microbiology 134, 1883-1892.

KushNER, S. R. (1978). An improved method for transformation of $E$. coli with ColE1-derived plasmids. In Genetic Engineering. pp. 1723. Edited by B. Boyer \& S. Nicosia. Amsterdam: Elsevier.

LatT, S. A., Holmquist, B. \& Vallee, B. L. (1969). Thermolysin: a zinc metalloenzyme. Biochemical and Biophysical Research Commumications 37, 333-339.

Levy, P. L., Paugburn, M. K., Burstein, Y., Ericsson, L. H., Neurath, H. \& Walsh, K. A. (1975). Evidence of homologous relationship between thermolysin and neutral proteases $A$ of $B$. subtilis. Proceedings of the National Academy of Sciences of the United States of America 75, 4341-4345.

Loshon, C. \& Setlow, P. (1982). B. megaterium spore protease: purification, radioimmunoassay, and analysis of antigen level and localization during growth, sporulation, and spore germination. Journal of Bacteriology 150, 303-311.

Maniatis, T., Fritsch, E. F. \& Sambrook, J. (1982). Molechlar Cloning: a Laboratory Manual. Cold Spring Harbor, NY: Cold Spring Harbor Laboratory.

Matthews, B., Jansonius, J., Colman, P., Schoenborn, B. \& Dupourque, D. (1972). Three-dimensional structure of thermolysin. Nature, London 238, 37-41.

Messing, J. (1983). New M13 vectors for cloning. Methods in Enzymology 101, 20-37.

Millet, J. (1968). Étude de la Mégatériopeptidase protéase exocellulaire de B. megaterium. I: Purification et propriétés générales. Bulletin de la Societé de Chimie Biologique 51, 61-68.

Millet, J. \& ArCher, R. (1969). Spécificité de la mégatériopeptidase: une amino-endopeptidase à caractère hydrophobe. European Journal of Biochemistry 9, 456-462.

Millet, J. \& Aubert, J.-P. (1969). Étude de la mégatériopeptidase. protéase exocellulaire de $B$. megaterium III: Biosynthèse et rôle physiologique. Annales de l'Institut Pasteur 117, 460-473.

Moran, C. P., Jr, Lang, N., Legrice, F. J., Lee, G., Stephens, M. Sonenshine, A. L., Pero, J. \& Losick, R. (1982). Nucleotide sequences that signal the initiation of transcription and translation in B. subtilis. Molecular and General Genetics 186, 339-346.

Nicaud, J. M., Mackmann, G. I. \& Holland, I. B. (1986). The Cterminal $23 \mathrm{kDa}$ peptide of $E$. coli haemolysin 2001 contains all the information necessary for its secretion by the haemolysin (Hly) export machinery. FEBS Letters 204, 231-235.

NishiYA, Y. \& Imanaka, T. (1990). Cloning and nucleotide sequence of the B. stearothermophilus neutral protease gene and its transcriptional activator gene. Journal of Bacteriology 172, 4861-4869.

Pauptit, R. A., Karlsson, R., Picot, D., Jenkins, J. A.. NiklausReimer, A.-S. \& JANSONius, N. (1988). Crystal structure of neutral protease from $B$. cereus refined at $3.0 \AA$ resolution and comparison 
with the homologous but more thermostable enzyme thermolysin. Journal of Molecular Biology 199, 525-537.

Perlman, D. \& Halvorson, H. O. (1983). A putative signal peptidase recognition site and sequence in eucaryotic and procaryotic signal peptides. Journal of Molecular Biology 167, 391-409.

Pugsley, A. P. (1988). Protein secretion across the outer membrane of Gram-negative bacteria. In Protein Transfer and Organelle Biogenesis, pp. 607-652. Edited by R. C. Das \& P. W. Robbins. Orlando. Florida: Academic Press.

Rufo, G. A., Sullivan, B. J., Sloma, A. \& Pero, J. (1990). Isolation and characterization of a novel extracellular metalloprotease from B. subtilis. Journal of Bacteriology 72, 1019-1023.

Saito, H. \& Miura, K. (1963). Preparation of trans-forming deoxy ribonucleic acid by phenol treatment. Biochimica et Biophysica Acta 72, 619-629.

Sanger, F., Nicklen, S. \& Coulson, A. R. (1977). DNA sequencing with chain-termination inhibitors. Proceedings of the National Academy of Sciences of the United States of America 74, 5463-5467.

Sidler, W., Niederer, E., Suter, F. \& Zuber, H. (1986). The primary structure of $B$. cereus neutral protease and comparison with thermolysin and B. subtilis neutral proteinase. Biological Chemistry Hoppe-Seyler 367, 643-657.

Skerman, V. B. D., McGowan, V. \& Sneath, P. H. A. (1980). Approved lists of bacterial names. International Journal of Systematic Bacteriology 30, 225-420.

Sloma, A., Rudolph, C. F., Rufo, G. A., Jr, Sullivan, B. J., Theriault, K. A., Ally, D. \& Pero, J. (1990). Gene encoding a novel extracellular metalloprotease in B. subtilis. Journal of Bacteriology 172, 1024-1029.

SOUtherN, E. M. (1975). Detection of specific sequences among DNA fragments separated by gel electrophoresis. Journal of Molecular Biology 98, 503-517.

Stahl, M. L. \& Ferrari, E. (1984). Replacement of the B. subtilis subtilisin structural gene with an in vitro derived deletion mutation. Journal of Bacteriology 158, 411-418.
Staufer, C. E. (1971). The effect of $\mathrm{pH}$ on thermolysin activity. Archives of Biochemistry 147, 568-570.

TaKaGi, M., Imanaka, T. \& Aiba, A. (1985). Nucleotide sequence and promoter region for the neutral protease gene from $B$. stearothermophilus. Journal of Bacteriology 163, 824-831.

Tinoco, I., Jr., Borer, P. N., Dengler, B., LeVin, M. D. Uhlinbeck, O. C., Crothers, D. M. \& Graller, J. (1973). Improved estimation of secondary structure in ribonucleic acids. Nature New Biology 246. $40-41$.

Titani, K., Hermodson, M., Ericsson, L., Walsh, K. \& Neurath, H. (1972). Amino acid sequence of thermolysin. Nature, London 238. $35-37$.

Tran, L., Wu, X.-C. \& WONG, S.-L. (1991). Cloning and expression of a novel protease gene encoding an extracellular neutral protease from B. subtilis. Journal of Bacteriology 173, 6364-6372.

Vasantha, N., Thompson, L. D., Rhodes. C., Banner, C.. Nagle, J. \& Filpula, D. (1984). Genes for alkaline protease and neutral protease from $B$. amyloliquefaciens contain a large open reading frame between the regions coding for signal sequence and mature protein. Journal of Bacteriology 159, 811-819.

Wong, S.-L., Price, C. W., Goldfarb, D. S. \& Doi. R. H. (1984). The subtilisin $\mathrm{E}$ gene of $B$. subtilis is transcribed from a sigma ${ }^{37}$ promoter in vivo. Proceedings of the National Academy of Sciences of the United States of America 81, 1184-1188.

Wu, X.-C., Nathoo, S., Pang, A. S.-H., Carne. T. \& Wong, S.-L. (1990). Cloning, genetic organization, and characterization of a structural gene encoding bacillopeptidase $\mathrm{F}$ from $B$. subtilis. Journal of Biological Chemistry 265, 6845-6850.

YanG, M. Y., Ferrari, E. \& Henner, D. J. (1984). Cloning of the neutral protease gene of $B$. subtilis and the use of the cloned gene to create an in vitro-derived deletion mutation. Journal of Bacteriology. 160, 15-21.

Yoshimoto, T., Oyama, H., Takeshita, T., Higashi, H.. Lin Xu. S. \& Tsuru, D. (1990). Nucleotide sequence of the neutral protease gene from B. subtilis var. amylosacchariticus. Journal of Fermentation and Bioengineering 70, 370-375. 